\title{
Alarming challenges threatening the future world population and food security: an effective solution, cultivation of the halophytic plant species
}

\section{Editorial}

Population growth, climatic change, global warming, industrialization, conversion of the arable lands to abundant unusable for agricultural activities and crop production for food security are the most challenging issues facing human beings, animals, plants, and overall life on the earth. It has been predicted that the population growth throughout the word, particularly population explosion in the third world countries will result in the current over 7billion world population to increase about 2billion by the year 2050 and it will reach over 9 billion. Considering the above challenges, feeding the increased world population with the decreased arable agricultural lands makes it extremely difficult to provide food and feed the future world population. Agricultural soils salinization and shortage of water due to the above problems mandates use of saline soils and low quality/saline waters for irrigation and cultivation of plant species with high degrees of salinity and drought tolerances. Thus, there is an urgent need for finding salt and drought tolerant plant species to survive under the harsh and unfavorable conditions. My extensive investigations through the years indicated that halophytic plant species such as bermudagrass (Cynodon dactylon L.), alkali sacaton grass (Sporobolus airoides Torr.), Seashore paspalum (Paspalum Vaginatum Swartz), and saltgrass (Distichlis spicata L.) have a great potential to be used under harsh and stressful environmental conditions, yet have satisfactory growth and production. These halophytic plant species have numerous usages, including, biological reclamation of the saline soils, soil erosion control, and combating desertification processes, animal feed, and used for landscaping. The halophytic plants by removing the salts from the soil (biological reclamation of saline soils) can make the soil less saline and suitable for more productive and agronomic plant/crop species, a path to conversion of the saline soils to arable productive agricultural lands by biological reclamations. This will increase the agricultural land acreage for farming and crop production, resulting in a substantial food and feed production, a step for food security that is a major concern among all the scientists and experts in the agricultural fields. Extensive research on the adverse

\author{
Volume 6 Issue 5 - 2017
}

\section{Mohammad Pessarakli}

Department of Plant Sciences, The University of Arizona, Tucson, USA

Correspondence: Mohammad Pessarakli, Department of Plant Sciences, The University of Arizona, USA

Email pessarak@email.arizona.edu

Received: March 16, 2017| Published: March 17, 2017

effects of the environmental stresses, biotic and abiotic, on plants growth and productivity will lead to identifying the plant/crop species tolerant to the harsh growth conditions that are inevitable in the future. The findings of the research on this area may be the only solution to solve the global food shortages in the future. In short, the halophytic plant species can successfully and effectively be used as cover plant species to prevent soil erosion, combat desertification, biologically reclaim saline soils and convert them to arable agricultural farmlands for food and feed production. In addition, they reduce the carbon dioxide $\left(\mathrm{CO}_{2}\right)$ generated via industrialization by using it through photosynthesis, also they can prevent the dust storms that are transporting the soils from the bare areas to residential and farmlands, therefore improving the quality of the environment, an additional health benefit.

\section{Acknowledgements}

None.

\section{Conflict of interest}

The author declares no conflict of interest. 